\title{
4
}

\section{New Biologic Drugs for Ulcerative Colitis}

\author{
Francesca Zorzi, Emma Calabrese and Francesco Pallone \\ Gastrointestinal Unit, Department of Internal Medicine, University of Rome Tor Vergata, \\ Italy
}

\section{Introduction}

Inflammatory bowel diseases (IBD) are chronic remittent or progressive inflammatory conditions that may affect the gastrointestinal tract. Crohn's disease (CD) and Ulcerative colitis (UC) are two main phenotypes of IBD. Their etiopathogenesis has not been elucidated but is thought to involve a complex interplay among genetic, environmental, microbial and immune response (1). In the last two decade the advances in our knowledge of the pathogenesis mechanism underlying chronic inflammation in the gut, together with the increase progress in biotechnology have led to the development of a number of biological agent that selectively target specific molecules and pathway involve in gut inflammation. We briefly review the mechanism of action and the efficacy of biological agent in UC.

\section{Pathogenetic background}

\subsection{Genetics factors}

Both types of IBD occur in genetically susceptible individuals. IBD, considered a polygenic disorder, is familial in $5-10 \%$ and sporadic in the remainder (2). In UC phenotypic concordance in monozygotic twins is less frequent (10-20\%) than in CD (50-70\%), suggesting that the environmental factors play a more important role. Genetic studies, including genome wide association studies (GWASs) have improved our knowledge on the importance of genetic susceptibility in IBD. Interesting GWASs revealed a substantial overlap in genetic risk factors between CD and UC (3). However it is possible that this similitude is not shared at the level of structurally or functionally relevant polymorphisms. However some loci are quite unique for UC or for CD. For example loci related to regulatory pathways (IL10) intestinal epithelial cell function (ECM1) and HERC2 appear to be specific for UC. A striking outcome of GWASs is that the vast majority of identified loci individually confer a modest risk (odds ratios 1.11 and 1.29). The genetic basis for sporadic IBD may be due to the cumulative effect of interaction of unknown quantities of potentially thousands of common single nucleotide polymorphisms of minor individual biologic impact.

\subsection{Environmental factors}

The discordance of IBD among monozygotic twins and the development of IBD in immigrants to high prevalence countries and in countries under going rapid Westernization also highlight the importance of environmental factors in disease pathogenesis. Elements within a changing environmental that might affect development of the mucosal immune 
system and the enteric microflora include improved hygiene, consummation of sterile and no fermented foods, vaccination and age at first exposure to intestinal pathogens (4). The effects of poorly hygiene at early childhood are diverse; in some situation poor hygiene can lead to increase pathogenic infections, but in others it results in a higher exposure to harmless microorganisms and priming of the regulatory immune system, thus lowering the risk for development of IBD. Other environmental factors could affect the disease phenotype is the cigarette smoking that has an opposite effect on the outcome of each form of IBD, most reports have shown that no smoking is a feature of patients in UC, whereas smoking is a feature of CD patients (5-6). A cigarette smoking has been shown to affect cellular ad humoral immunity (7-8), and to increase mucous production (9). Results from in vivo studies have shown that nicotine also has an inhibitory effect on Th2 function that predominates in UC.

\subsection{Microbial flora}

The contest of the intestinal lumen plays a central role in gut homeostasis. The gastrointestinal tract harbors more than $10^{14}$ microorganisms of more than 1000 species. Most belong to two different phyla that account for the majority of gram-negative bacteria (bacterioides) and gram-positive bacteria (Firmicutes). Collectively, the microbiota carries out many physiological functions important in mammalian biology. In fact, the microbiota is required for the development and differentiation of local and systemic immune and nonimmune components (10). Systemic immune responses are also impaired in germ-free mice, including the development of adequate Treg responses leading to increased systemic autoimmunity (11), which may have implication for the development of extraintestinal manifestation in IBD. Luminal bacteria appear to provide the stimulus for immunoinflammatory responses leading to mucosal injury. In IBD mucosal production of IgG antibodies against intestinal bacteria is highly increased, and mucosal defense relies on both IgG mediated responses within the tissue and hyperactivated lymphocytes in the lamina propria reacting against bacterial antigens. These combined events result in inflammation and tissue injury. The altered immune response is not specifically addressed or polarized toward a single group of potential pathogens, but involves a large and undefined number of commensal species belonging to the common enteric flora. Several factors may contribute to the abnormal reactivity of the mucosal immune system against enteric bacteria, and these include genetic susceptibility, a defect in mucosal barrier function, and a microbial imbalance in the gut ecosystem (1).

Several studies have shown that the composition of the fecal microbiota differs between subjects with IBD and healthy controls. The reported differences are variable and not always consistent among the various studies. However, molecular studies show that a substantial proportion of fecal bacteria (up to $30 \%-40 \%$ of dominant species) in patients with active IBD belong to phylogenetic groups that are unusual in healthy subjects (12).

\subsection{Immuno-inflammatory factors}

This complex interaction of genetic, environment and microbial factors culminates in a sustained activation of the mucosal immune and non immune response resulting in active chronic inflammation and tissue damage (1).

In the healthy gut the mucosal immune system maintains a balance between pro- and antiinflammatory factors, thereby allowing an effective defense against luminal pathogens 
while simultaneously preventing an overactive immune response. In IBD, this balance is altered with a shift toward a proinflammatory state owing to a deregulated immune system with a complex interplay between effect and regulatory $\mathrm{T}$ cells and immunosuppressive and proinflammatory cytokines (13).

\section{Definition of biologic therapy}

The promise of biologic therapy is the direct translation of the knowledge of basic mechanisms of disease into therapies of enhanced specificity. Biologic therapies encompass agents of diverse modes of action. Biologic therapies may be considered to fall under five broad categories: (a) native biologic preparations and isolates, included proteins isolated from blood or serum, such as clotting factors or immune globulins, as well as classic vaccines incorporating live, attenuated, or killed microorganisms, or their isolated subunits; (b) recombinant peptides or proteins, many diverse classes of peptides and proteins with the shared feature of having been produced in recombinant cell-based systems, such as bacteria, yeast, or mammalian cells in culture. Most important are recombinant cytokines, cytokine receptor antagonists, and soluble receptors for cytokines and other relevant ligands; (c) antibody-based therapies, monoclonal antibodies may be used for therapeutic purposes, but their utility may be limited by the development of humoral immunity against these nonnative proteins; (d) nucleic acid-based therapies, the most promising agents of this type are antisense oligonucleotides. These agents consist of synthetic oligonucleotides of singlestranded DNA bearing a sequence complementary to that of a targeted mRNA species. (e) Cell and gene therapies, include techniques that may alter autologous or donor cell populations. This category may include the treatment of targeted cells with various factors or cytokines ex vivo, or the insertion or deletion of targeted genes in isolated cells ex vivo followed by reintroduction into the host. Alternatively, genetic manipulation may be accomplished by means of viral or plasmid vectors in vivo (14).

\section{New biologic drugs for UC}

\subsection{Blockade of T-cell activation}

$\mathrm{T}$ cell activation requires two signals. The first signal is mediated by the interaction of the $\mathrm{T}$ cell receptor complex, with includes CD4 and CD3, with the antigenic peptides presented by major histocompatibility complex molecules on the surface of antigen presenting cells; the second signals (the costimulatory signals), is antigen non specific and is provided by the interaction between costimulatory molecules expressed on the membrane of antigen presenting cells and the $\mathrm{T}$ cell, activation of $\mathrm{T}$ cell without costimulatory signals leads to $\mathrm{T}$ cell anergy, deletion or immune tolerance.

\subsubsection{Anti CD4+ antibodies}

Anti CD4 antibodies have been used in a variety of autoimmune disease, and have been tested in CD and UC. A CD4 depleting antibody (cM-T412) was tested in one open label study in UC patients achieved clinical and endoscopic improvement/remission after a period of treatment ranging from seven to eleven days (15). In another three open trials a CD4 no depleting antibodies (MAX.16H5 and B-F5) were administered to nine UC patients with active disease; of the nine patients, five achieved remission. Thus, CD4 depleting antibodies seem to be more effective than no depleting antibodies therapy. However, this 
specific treatment was most associated with a significant decrease in CD4 cells, and because of concerns of CD4 lynmphopenia no further studies have been performed $(16,17)$.

\subsubsection{Anti CD3+ antibodies}

Visilizumab (HuM291) is a non-fragment crystallized region (FcR) binding anti CD3 monoclonal antibody directed against invariant $\mathrm{CD} 3 \varepsilon$ chain of the $\mathrm{T}$ cell receptor; this compound was studied in patients with severe refractory UC. In an open label phase I/II trials, eight patients received a $15 \mu \mathrm{g} / \mathrm{Kg}$ intravenous bolus dose of Visilizumab on two consecutive days and two others received $10 \mu \mathrm{g} / \mathrm{Kg}$. Remission was achieved after 1 month in seven of the eight patients in the $15 \mu \mathrm{g} / \mathrm{Kg}$ group and after 15 days in all patients in the $10 \mu \mathrm{g} / \mathrm{Kg}$ group. All 8 patients in the high dose group showed improvement based on endoscopic assessment. Endoscopic lesions were absent or only mild in six out of eight patients, and most patients in remission managed to fully taper off their concomitant steroids treatment. An extension of these original trials comprised a total of 24 patients treated with $10 \mu \mathrm{g} / \mathrm{Kg}$ Visilizumab. On day 30 clinical improvement, remission rate and endoscopic remission were observed in $84 \%, 66 \%$ and $44 \%$ of patients. After one year, ten out of 22 patients did not require surgical or medical salvage therapy and colectomies were performed for intractable colitis in seven patients during follow up evaluation with a median time to colectomy of 160 days (18). However a phase III randomized double blind placebo controlled multicenter study of Visilizumab in patients with intravenously steroids refractory ulcerative colitis was withdrawn and the Visilizumab was terminated because an interim analysis showed no difference in colectomy rates from Visilizumab versus placebo (19).

\subsubsection{Anti IL2-receptor (CD25)}

CD25 is a membrane receptor expressed by activated T lymphocytes. IL-2 is a cytokine produced by $\mathrm{T}$ cells that induced lymphocyte proliferation and clonally expansion. Cyclosporine, a calcineurin inhibitor, which inhibits IL-2, is effective for the treatment of severely active ulcerative colitis; therefore it was proposed that blocking IL-2 would be an effective therapy for ulcerative colitis (20).

Daclizumab (Zanapax, Protein Designed Labs) is a recombinant humanized IgG1 monoclonal antibody to IL-2 receptor, witch blocks the binding of IL-2 to the receptor (CD25). In an open label pilot trial, ten patients were included and were given two intravenous doses $(1 \mathrm{mg} / \mathrm{Kg})$ with 4 weeks interval between doses. Promising response rates at 8 weeks suggested that it was beneficial for patient with active UC (21). Subsequently a randomized double blind placebo control trial was conduced to evaluate the efficacy of induction therapy with Daclizumab in active UC patients. One hundred and nine patients with moderate UC were assigned randomly to groups that were given intravenously $1 \mathrm{mg} / \mathrm{Kg}$ dose at weeks 0 and $4 ; 2 \mathrm{mg} / \mathrm{Kg}$ dose at weeks 0,2,4 and 6 compared with patients that received placebo. At week 8 remissions and responses respectively were observed in $2 \%$ and $25 \%$ of patients receiving Daclizumb $1 \mathrm{mg} / \mathrm{Kg}$ and $7 \%$ and $33 \%$ of patients receiving $2 \mathrm{mg} / \mathrm{Kg}$ compared with $10 \%$ and $44 \%$ of those received placebo. Daclizumab failed to show any efficacy in active UC (22).

Basilizumab (Simulect, Novartis), a chimeric anti CD25 monoclonal IgG1 antibody was evaluated only in open label pilot trial. Fifteen patients received Basilizumab in addition to their standard steroid treatment to evaluate the efficacy of treatment as a steroids sensitizing 
agent in steroid-resistant UC. Eighty per cent of patients achieved remission within 6 weeks (23). Basilizumab was evaluated only in open label trials and the data might show efficacy but larger placebo controlled trials are needed.

\subsubsection{Abadacept}

Abatacept modulates naïve T-cell activation and downstream cytokine production. It is a fully human, soluble fusion protein, which consists of the extracellular domain of human cytotoxic T-lymphocyte-associated antigen-4 (CTLA-4) linked to the Fc portion of human immunoglobulin G1. The CTLA-4 portion of the molecule interrupts the CD80/ CD86:CD28 costimulatory signal, mimicking a native homoeostatic mechanism of T-cell down regulation. It is effective in treating patients with rheumatoid arthritis and phase III trials are underway to test its effects in patients with UC and CD.

\subsection{Inflammatory cytokines}

\subsubsection{Anti tumor necrosis factors}

TNF-a is a proinflammatory cytokine that has a critical role in the amplification of mucosal inflammation in IBD. TNF- $\alpha$ acts as transmembrane or soluble proteins by transducing signals ranging from cellular activation and proliferation to cytotoxicity and apoptosis through two distinct TNF receptors (TNFR1 and TNFR2). The currently most efficacious treatment for IBD is anti-TNF antibodies. Actually three anti TNF molecules are studied to treat UC.

Infliximab is a monoclonal chimeric antibody, targeting TNF-a composed of a human constant region IgG1K light chain, accounting for approximately $75 \%$ of antibody, linked to a mouse variable region (25\%). Initially Infliximab did not seem to have much therapeutic effect on UC. Two small pilot trials showed disappointing results for the drug in the treatment of refractory UC (24-25). Recently a new role of Infliximab in the treatment of UC has been offered by two large placebo controlled trials ACT1 and ACT2 (26). In the ACT1 364 patients with active UC with endoscopic evidence of moderate-severe were randomly assigned to receive placebo or Infliximab $5 \mathrm{mg} / \mathrm{Kg}$ or $10 \mathrm{mg} / \mathrm{Kg}$ at weeks $0,2,6$ and every 8 weeks through to week 46 . At week $838,8 \%$ patients receiving $5 \mathrm{mg} / \mathrm{kg}$ dose and $32 \%$ of patients receiving the higher dose achieved remission comparing $14.9 \%$ of patients receiving placebo. This difference in remission rates was maintained at week $30(33.9 \% 5 \mathrm{mg} / \mathrm{kg}$, $36.9 \% 10 \mathrm{mg} / \mathrm{kg}$ versus $15.7 \%$ placebo). Mucosal healing was achieved at weeks 8 and 30 respectively in $62 \%$ and $50.4 \%$ in the lower dose group, in $59 \%$ and $49.2 \%$ in the higher dose, and in $33.9 \%$ and $24.8 \%$ in the placebo group. In the ACT2 study 364 UC patients, refractory to at least one standard therapy were randomly assigned to receive placebo or Infliximab 5 $\mathrm{mg} / \mathrm{Kg}$ or $10 \mathrm{mg} / \mathrm{Kg}$ at weeks $0,2,6,14$ and 22. Clinical remission evaluated at week 8 and 30 were respectively $33.9 \%$ and $25.6 \%$ in $5 \mathrm{mg} / \mathrm{kg}$ Infliximab group, $27.5 \%$ and $35.8 \%$ in 10 $\mathrm{mg} / \mathrm{Kg}$ Infliximab group versus $5.7 \%$ and $10.6 \%$ in the placebo group. Mucosal healing was achieved at weeks 8 and 30 respectively in $60.3 \%$ and $46.3 \%$ in the lower dose group, in $61.7 \%$ and $56.7 \%$ in the high dose group, and in $30.9 \%$ and $30.1 \%$ in the placebo group. In both trials Infliximab was well tolerated and induces and maintains clinical response and mucosal healing in moderate to severe UC patients.

Adalimumab is a fully human IgG1 monoclonal antibody to TNF-a that is administrated subcutaneously and easily can be self administrated every 2 weeks. In the first randomized double-blind controlled trial of efficacy and safety of Adalimumab for the induction of 
clinical remission in 390 patients with moderate to severe active UC (27). Patients were administrated either with placebo or Adalimumab every two weeks for a total of four doses over a 6 week period. Adalimumab was administrated according to one of the following dosage scheduled: 1) $160 \mathrm{mg}$ at week $0,80 \mathrm{mg}$ at week 2 and $40 \mathrm{mg}$ at week 4 and 6;2) 80 $\mathrm{mg}$ at week 0 and $40 \mathrm{mg}$ at weeks 2,4 , and 6 . At week $8,18.5 \%$ of patients received Adalimumab 160/80/40 mg had achieved remission ( $\mathrm{p}=0.031$ verso placebo), which was significantly greater proportion than those patients received Adalimumab 80/40 mg $(10 \%)(0.833$ verso placebo) or placebo $(9.2 \%)$. No significant differences were observed in the rate of serious adverse events. Adalimumab was therefore well tolerated and effectively induced remission in approximately one-fifth of patients with moderate to severe active UC. In this trial numerous secondary end points were also positive for the higher dose of Adalimumab. Despite the relative poor comparative performance of Adalimumab that, perhaps, suggests inadeguate dosing in the UC trials, several open-label series have reported benefits from Adalimumab in UC patients who responded, but became intolerant of Infliximab. $(28,29)$.

RDP58 is a novel anti-inflammatory decapeptide able to clock TNF production at a post transcriptional step (30) and also inhibits production of IFN- $\gamma$, IL-2 and IL-12. RDP58 has been shown to be effective in murine and primate models of colitis $(31,32)$. In a phase II study 127 patients with mild moderate UC were randomly assigned to receive placebo or an oral solution of RDP58 at 100, 200 or $300 \mathrm{mg}$ daily for 28 days. Clinical remission was achieved in $72 \%$ of patients in the $300 \mathrm{mg}$ group, $70 \%$ of patients in the $200 \mathrm{mg}$ group and $29 \%$ in the lower dose exhalation versus the placebo group. There were any differences in adverse events among treatments group compared to placebo group (33).

\subsubsection{Immunomodulators: reconbinant human Interferon $\alpha$ and $\beta$}

IFNs $\alpha$ and $\beta$ are produced by virally infected cells and inhibit viral replication within host cells, activate natural killer cells and macrophage, and increase antigen presentation to lymphocytes. IFNs $\alpha$ and $\beta$ have been investigated in UC with no success. In a multicenter double blind placebo controlled trial, patients with moderate active UC were randomized to receive two doses of INF- $\beta$-1a (44 and 66 mcg subcutaneously 3 times weekly for 8 weeks) versus placebo. No differences between INF- $\beta-1 \mathrm{a}$ and placebo were observed at 12 weeks (34).

\subsection{Anti inflammatory cytokines}

IL-10 is an anti-inflammatory cytokine produced by T cells, B cells and monocyte activated lipopolysaccharides. When the body is presented with an antigen, IL-10 inhibits the production of IL-1a, IL- 6 and TNF- $a$. Thus, it contributes to down regulation of acute inflammatory responses (13) In animal models, IL-10 maintains immune homeostasis in the gut and may play a role in the treatment of IBD (35). A phase II placebo-controlled dose response trial with recombinant IL-10 (rHuIL-10) failed to show a beneficial effect in 94 UC patients with mild to severe active disease (36). Development of systemic administration of rHuIL-10 for IBD was discontinued because of lack of efficacy in controlled trials but other animal studies showed that local administration of IL-10 to the colon via genetically engineered Lactococcus lactis bacteria that are administered orally allows for the achievement of high colonic mucosal concentration of IL-10, resulting potentially in increased efficacy. It 
is possible that this approach to IL-10 therapy will be an alternative therapeutic approach for IBD (37).

\subsection{Selective adhesion molecule inhibitors}

Leukocyte adhesion in high endothelial venules of the gut is a multistep process. Fast moving immune cells are first slowed down by interaction of selectins and non-activated integrins with their respective ligands expressed by endothelial cells. This causes tethering and rolling of leukocytes close to the endothelial surface. Chemokines secreted from sites of inflammation diffuse through the endothelial layer, bind to chemokine receptors and activate integrins. Firm adhesion is the last step before leukocyte diapedesis through endothelial pores and results from strong binding between activated a $4 \beta 7$ integrins with their ligand, mucosal addressing cellular adhesion molecule-1 (38). Agent that block interaction between adhesion molecules on circulating immune cells and their endothelial cell receptors wound be expected to decrease the migration of these cells through the endothelium, thereby decrease chronic inflammation (39).

Natalizumab is a recombinant humanized IgG4 monoclonal antibody to a4 integrin that block adhesion and subsequent leukocyte migration into the gut. It inhibits both a4 37 integrin/MAdCAM-1 interaction and a4 $37 /$ VCAM-1 binding. Natalizumab 3mg/Kg single intravenous infusion has also demonstrated some evidence of clinical benefit at two weeks post infusion in an uncontrolled study in 10 patients with active UC. Five out of 10 patients achieved a good clinical response at 2 weeks and one more patients at 4 weeks, defined by a Powell-Tuck score of $\leq 5(40)$. Natalizumab was withdrawn voluntarily from the marked in February 2005 for safety evaluation after one fatal and one non fatal case of progressive multifocal leukoencephalopathy (PML) occurred in the group of 1869 patients who were treated with Natalizumab in combination with Interferon- $\beta$-1a over a 2 years period for treatment of multiple sclerosis. Although the 3 case of PML, a review by Youry et al of more than 3000 patients who have received Natalizumab for multiple sclerosis, CD or rheumatoid arthritis suggested a risk of PML of 1/1000 patients treated with Natalizumab for a mean duration of 17.9 months (41). Natalizumab was reintroduced to the market for multiple sclerosis and CD in the United States.

Vedolizumab (formerly MLN-02 and LDP-02) is a humanized anti- $\alpha 4 \beta 7$-integrin antibody MLN-0002, that selectively inhibits leukocyte adhesion in the gastrointestinal mucosa. Therefore this compound is being developed only in IBD. A fase I/II, double blind, place controlled, ascending dose trial examined the safety and pharmacology of MLN-0002 in 28 UC patients with moderate severe disease (42). Patients received a single dose of 0.15 $\mathrm{mg} / \mathrm{kg}$ s.c., a single dose of $0.15,0.50$, or $2.0 \mathrm{mg} / \mathrm{kg}$ e.v. or placebo. MLN_0002 appeared to be a generally well-tolerated and effective therapy for active UC. Four years later a multicenter double blind placebo controlled trial was performing involving 181 patients with active UC confirmed efficacy of MLN-0002 in the treatment of active disease. Patients were treated with 2 intravenous dose, 28 days apart, of $0.5 \mathrm{mg} / \mathrm{kg}$ or $2.0 \mathrm{mg} / \mathrm{Kg}$ of MLN0002 or placebo. At week 6, clinical remission rates were $33 \%, 32 \%$ and $14 \%$ in the groups given $0.5 \mathrm{mg} / \mathrm{Kg}$ of MLN-0002, $2.0 \mathrm{mg} / \mathrm{kg}$ of MLN-0002 and placebo respectively; percentage of patients who improved by at least 3 points on UC clinical score were respectively $66 \%, 53 \%$ and $33 \%$. Remission was observed by endoscopy in $28 \%$ in the lower dose of MLN-0002, in 12\% in the higher dose group compared with $8 \%$ in the placebo group (43). 
The interaction of lymphocyte-associated $\alpha_{1} \beta_{2}$-integrin and its ligand ICAM-1 (Intracellular adhesion molecule-1) is important for the recruitment of leukocytes to inflammatory sites. Alicaforsen (ISIS 2302) is a 20-base phosohorothioate antisense oligodeoxynucleotide. It is designed to hybridize to a 3' untranslated region of human ICAM-1 messenger ribonucleic acid (mRNA). The heterodimer formed is cleaved by ubiquitous ribonuclease $\mathrm{H}$, resulting in a reduction in ICAM-1 protein expression (44). Initial positive results in CD patients reported in a pilot study were not confirmed in two subsequent placebo controlled trial (4547). Instead in a placebo controlled trial with ISIS 2302 in enema formulation showed significant improvement in 40 patients with distal UC (48). In a phase 2, dose-ranging, double-blind, placebo-controlled study, 112 patients with mild-moderate left-sided UC received one of four ISIS 2302 enema regimens or placebo daily for 6 weeks (49). While there were no significant differences between treatment or placebo in terms of DAI at week 6, there was a prolonged reduction in the mean percentage DAI relative to baseline from week $18(51 \%$ versus $18 \% \mathrm{p}=0.04)$ to week $30(50 \%$ versus $11 \% \mathrm{p}=0.03)$ in the $240 \mathrm{mg}$ ISIS 2302 group compared with placebo.

Monoclonal antibodies to Madcam-1 and integrin $\beta 7$ subunit (50) are currently being tested in clinical trials..

\subsection{Growth factors}

Epithelial growth factors are naturally occurring proteins capable of stimulating cellular growth, proliferation and differentiation. A potent mitogenic peptide produced by salivary glands, epidermal growth factors (EGF) and keratinocyte growth factor (KGF) may play an important role in IBD for their potential use to restore mucosal integrity (51). In UC the inflammation is confined to the mucosa and epithelial cell damage is an important feature.

Repifermin (KGF-2) has been shown to reduce inflammation in animal models of colitis (52-54). The effect of Repifermin were studied in a phase II, placebo controlled trial in 88 patients with active UC. Patients were randomized to receive treatment for five consecutive days with intravenous repifermin at a dose of $1,5,10,25$ or $50 \mathrm{lg} / \mathrm{kg}$, or placebo. Intravenous repifermin at a dose of $1-50 \mu \mathrm{g} / \mathrm{kg}$ was very well tolerated, but there was no evidence that repifermin was effective for the treatment of active UC at these doses (55).

In randomized, double-blind clinical trial conducted, 12 patients with mild-to-moderate left-sided UC received daily enemas of $5 \mu \mathrm{g}$ of EGF in $100 \mathrm{ml}$ of an inert carrier and 12 patients received daily enemas with carrier alone for 14 days, all patients also began to receive 1.2 gr of oral mesalamine per day or had their dose increased by 1.2 gr per day. After two weeks, 10 of the 12 patients treated with EGF enemas were in remission, as compared with 1 of 12 in the control group (83 percent vs. 8 percent, $\mathrm{P}<0.001$ ). At the 2 week assessment, disease-activity score, endoscopic score and histology score were all significantly better in the EGF group than in the placebo group $(p<0.01$ for all comparisons), and this benefit was maintained at 4 and at 12 weeks. This study provides preliminary data suggesting that EGF enemas are an effective treatment for active leftsided UC (56). Further studies are warranted, but the safety of therapy stimulating EGF in $\mathrm{UC}$ is most importantly because it up regulates the expression of protoncogen in patients with known colon cancer risk. 


\section{Conclusion: The state of art biologic agent in UC}

Over the last two decades, advances in bio-technology together with the increasing knowledge about the pathogenesis of IBD and the mechanism driving the uncontrolled inflammation led to discovery new targets for a large number of biological agents. The improved understanding of pathogenic mechanisms and the basis of heterogeneity within the disease group should lead to different therapeutic approaches for various disease phenotypes and eventually to personalize treatment. The benefits for anti-TNF therapy in UC have opened the door of clinical practice for additional anti-TNF or for agents with alternative targets. Early studies have suggested potential benefits of inhibiting adhesion molecules such as $\alpha 4 \beta 7$ integrins or inhibition of ICAM- 1 ; on the other hand studies evaluating therapies targeting $\mathrm{T}$ cell activation have been disappointing. Finally, given that the efficacy, short-term and long term for the newer biological therapeutics are either limited or remain to be proven on a large number of patients, the use of such agents in patients remains to be estimated and tailored on the single patient.

\section{References}

[1] Kaser A, Zeissing S, Blumberg RS. Inflammatory Bowel Disease. Annu Rev Immunol. 2010;28:573-621.

[2] Halme L, Paavola-Sakki P, Turunen U, et al. Family and twin studies in inflammatory bowel disease. World J. Gastroenterol. 2006;12:3668-72.

[3] Budarf ML, Labbe C, David G, et al. GWA studies: rewriting the story of IBD. Trends Genet. 2009;25:137-46.

[4] Shanahnan F. Crohn's Disease. Lancet. 2002;359:62-69.

[5] Franceschi S, Panza E, La vecchia C, et al. Non specific inflammatory bowel disease and smoking. Am J Epidemiol. 1987;125:445-452.

[6] Linberg E, Tysk C, Anderson K, et al. Smoking and Inflammatory bowel disease: a case control study. Gut. 1988;29:252-357.

[7] Miller LG, Goldstein G, Murphy M, et al. Reversible alteration in immunoregulatory T cells in smoking: analysis by monoclonal antibodies and flow cytometry. Chest.1982;82:526-529.

[8] Srivastava ED, Barton JR, O'Mahony S. Smoking, humoral immunity, and ulcerative colitis. Gut. 1991;32:1016-1019.

[9] Cope GF, Heatley RV, Kelleher JK. Smoking and colonic mucous in ulcerative colitis. BMJ. 1986;293:481.

[10] Round JL, Mazmanian SK. The gut microbiota shapes intestinal immune responses during health amd diseaseNat Rev Immunol. 2009X

[11] Mazmanian SK, Round JL, Kasper DL. Amicrobial symbiosis factor prevents intestinal inflammatory disease. Nature. 2008;453:620-625

[12] Ott SJ, Musfeld M, Wenderoth DF, et al. Reduction in diversity of the colonic mucosa associated bacterial microflora in patients with active inflammatory bowel disease. Gut 2004;53:658-693

[13] Izcue A, Coombes JL, Powrie F. Regulatory Lymphocytes and Intestinal Inflammation. Annu Rev Immunol. 2009;27:313-338.

[14] Sands BE. Biologic therapy for inflammatory bowel disease. Inflamm Bowel Dis. 1997;3:95-113. 
[15] Deusch K, Mauthe B, Reiter C, et al. CDA-antibody treatment of inflammatory bowel disease: one year follow-up. Gastroenterology. 1993;104:A691

[16] Emmrich J, Seyfarth M, Fleig WE, et al. Treatment of inflammatory bowel disease with anti-CD4 monoclonal antibody. Lancet 1991; 338:570-571

[17] Emmrich J, Seyfarth M, Liebe S, et al. Anti-CD6 antibody treatment in inflammatory bowel disease without a long $\mathrm{CD}^{+}{ }^{+}$-cell depletion. Gastroenterology. 1995;108:A815.

[18] Plevy SE, Salzberg BA, Van Assche G, et al. A phase I study of visilizuma, a humanized anti-CD3 monoclonal antibody, for treatment of severe steroid-refractory ulcerative colitis. Gastroenterology.2007;133:1414-1422.

[19] Sandborn WJ, Colombel JF, Frankel M, et al. Anti CD3-antibody visilizumab is not effective in patients with intravenous corticosteroid-refractory ulcerative colitis. Gut. 2010; Nov;59(11):1485-92.

[20] Van Assche G, D'Haens G, Noman M, et al. Randomized, double-blind comparison of 4 $\mathrm{mg} / \mathrm{kg}$ versus $2 \mathrm{mg} / \mathrm{kg}$ intravenous cyclosporine in severe ulcerative colitis. Gastroenterology 2003;125(4):1025-31.

[21] Van Assche G, Dalle I, Noman M, et al. Apilot study on the use of the ulcerative colitis. Am J Gastroenterol. 2003; 98:369-376.

[22] Van Assche G, Sandborn WJ, Feagan BG, et al. Daclizumab, a humanised monoclonal antibody to the interleukin 2 receptor (CD25), for the treatment of moderately to severely active ulcerative colitis: a randomised, double blind, placebo-controlled, dose ranging trial. Gut. 2006;55:1568-1574.

[23] Creed TJ, Norman MR, Probert CS, et al. Basiliximab (anti-CD25) in combination with steroids may be an effective new treatment for steroid-resistant ulcerative colitis. Aliment Pharmacol Ther. 2003;18:1865-1875.

[24] Chey WY, Hussain A, Ryan C, et al. Infliximab for refractory ulcerative colitis. Am J Gastroenterol. 2001;96:2373-2381.

[25] Sands BE, Tremaine WJ, Sandborn WJ, et al. Infliximab in the treatment of severe, steroid-refractory ulcerative colitis: a pilot study. Inflamm Bowel Dis. 2001;7:83-88.

[26] Rutgeerts P, Sandborn WJ, Feagan BG, et al. Infliximab for induction and maintenance therapy for ulcerative colitis. N Engl J Med. 2005;353:2462-2476.

[27] Reinisch W, Sandborn WJ, Hommes DW, et al. Adalimumab for induction of clinical remission in moderately to severely active ulcerative colitis. Gut. 2011; 60:780-787.

[28] Afif W, Leighton JA, Hanauer SB, et al.. Open-label study of adalimumab in patients with ulcerative colitis including those with prior loss of response or intolerance to infliximab. Inflammatory Bowel Dis. 2009; 15:1302-1307

[29] Oussalah A, Laclotte C, Chevaux JB, et al. Long-term outcome of adalimumab therapy for ulcerative colitis with intolerance or lost of response to infliximab: a singlecentre experience. Aliment Pharmacol Ther 2008; 28:966-972.

[30] Iyer S, Kontoyannis D, Chevrier D, et al. Inhibition of tumor necrosis factor mRNA translation by a rationally designed immunomodulatory peptide. J Biol Chem. 2000;275:17051-17057.

[31] Murthy S, Flanigan A, Coppola D, et al. RDP58, a locally active TNF inhibitor, is effective in the dextran sulphate mouse model of chronic colitis. Inflamm Res. 2002;51:522-531. 
[32] Bourreille A, Doubremelle $M$, de la Bletiere DR, et al. RDP58, a novel immunomodulatory peptide with anti-inflammatory effects. A pharmacological study in trinitrobenzene sulphonic acid colitis and Crohn's disease. Scand J Gastroenetrol. 2003;38:526-532.

[33] Travis SPL, Yap LM, Hawkey CJ, et al. RDP-58: novel and effective therapy, for ulcerative coltis: results of parallel, prospective, placebo- controlled trial. Am J Gastroenterol. 2003;98:S239.

[34] Pena-Rossi C, Schreiber S, Golubovic G, et al. Clinical trial: a multicenter, randomized, double-blind, placebo-controlled, dose-finding, phase II study of subcutaneous interferon-beta-1a in moderately active ulcerative colitis. Aliment Pharmacol Ther. 2008;28:758-767.

[35] Kuhn R, Lohler J, Rennick D, et al. Interleukin-10-deficient mice develop chronic enterocolitis. Cell. 1993;75:263-274

[36] Schreiber S, Fedorak NR, Wild G, et al. Ulcerative Colitis IL-10 Cooperative Study Group. Safety and tolerance of rHuIL-10 treat- ment in patients with mild/moderate active ulcerative colitis. Gastroenterology. 1998;114:A1080-A1081.

[37] Steidler L, Hans W, Schotte L, et al. Treatment of murine colitis by Lactococcus lactis secreting interleukin-10. Science. 2000;289:1352-1355.

[38] Butcher EC, Picker LJ. Lymphocyte homing and homeostasis. Science. 1996;272:60-66.

[39] Sandbirn WJ, Yednock TA. Novel approaches to treating inflammatory bowel disease: targeting alpha-4 integrin: Am J Gastroenterol. 2003; 98:2372-2382.

[40] Gordon FH, Hamilton MI, Donoghue S, et al. A pilot study of treatment of active ulcerative colitis with natalizumab, a humanized monoclonal anti- body to alpha- 4 integrin. Aliment Pharmacol Ther. 2002;16:699-705.

[41] Yousry TA, Major EO, Ryschkewitsch C, et al. Evaluation of patients treated with natalizumab for progressive multifocal leukoencephalopathy. N Engl J Med 2006; 354:924-933.

[42] Feagan BC, McDonald J, Greenberg G, et al. An ascending dose trial of a humanized A4B7 antibody in ulcerative colitis (UC). Gastroenterology. 2001;118:A874.

[43] Feagan BG, Greenberg GR, Wild G, et al. Treatment of ulcerative colitis with a humanized antibody to the alpha4beta7 integrin. N Engl J Med. 2005;352:2499-2507.

[44] Bennet CF, Condon TP, Grimm S, et al. Inhibition of endothelial cell adhesion molecule expression with antisense oligonucleotides. J Immunol. 1994;152:3530-3540.

[45] Yacyshyn BR, Bowen-Yacyshyn MB, et al. A placebo- controlled trial of ICAM-1 antisense oligonucleotide in the treatment of Crohn's disease. Gastroenterology. 1998;114:113-142.

[46] Schreiber S, Nikolaus S, Malchow H, et al. Absence of efficacy of subcutaneous antisense ICAM-1 treatment of chronic active Crohn's disease. Gastroenterology. 2001;120:1339-1346.

[47] Yacyshyn BR, Chey WY, Goff J, et al. Double-blind, placebo con- trolled trial of the remission inducing and steroid sparing properties of an ICAM-1 antisense oligodeoxynucleotide, alicaforsen (ISIS 2302), in active steroid dependent Crohn's disease. Gut. 2002;51:30-36.

[48] Van Deventer SJ, Tami JA, Wedel MK. A randomised, controlled, double-bind, escalating dose study of alicaforsen enema in ulcerative colitis. Gut. 2004;53:16461651. 
[49] Van Deventer SJH, wedel MK, Baker BF et al.A phase II dose ranging, double-blind, placebo-controlled study of alicarforsen enema in subjects with acute exacerbation of mild to moderate left-sided ulcerative colitis. Aliment Pharmacol Ther. 2006;23:1415-1425.

[50] Rutgeerts P, Fedorak R, Daniel W, et al. A Phase I Study of rHuMab Beta7 in Moderate to Severe Ulcerative Colitis (UC). Gastroenterology 2011; 140: A748.

[51] Beck PL, Podolsky DK. Growth factors in inflammatory bowel disease. Inflamm Bowel Dis. 1999;5:44-60.

[52] Sung C, Parry T, Riccobene T, et al. Pharmacologic and pharmacokinetic profile of repifermin (KGF-2) in monkeys and comparative pharmacokinetics in humans. AAPS Pharmsci 2002; 4(2): 1-10.

[53] Han DS, Li F, Holt L, et al. Keratinocyte growth factor-2 (FGF- 10) promotes healing of experimental small intestinal ulcer- ation in rats. Am J Physiol Gastrointest Liver Physiol 2000; 279(5): G1011-22.

[54] Miceli R, Hubert M, Santiago G, et al. Efficacy of keratinocyte growth factor-2 in dextran sulfate sodium-induced murine colitis. J Pharmacol Exp Ther 1999; 290(1): 464-71.

[55] Sandborn WJ, Sands BE, Wolf DC, et al Repifermin (Keratinocyte growth factor-2) for the treatment of active ulcerative colitis: a randomized, double-blind, placebocontrolled, dose-escalation trial. Aliment Pharmacol Ther 2003;17: 1355-1364.

[56] Sinha A, Nightingale J, West KP, et al. Epidermal growth factor enemas with oral mesalamine for mild-to-moderate left-sided ulcerative colitis or proctitis. $\mathrm{N}$ Engl J Med. 2003;349:350-357. 


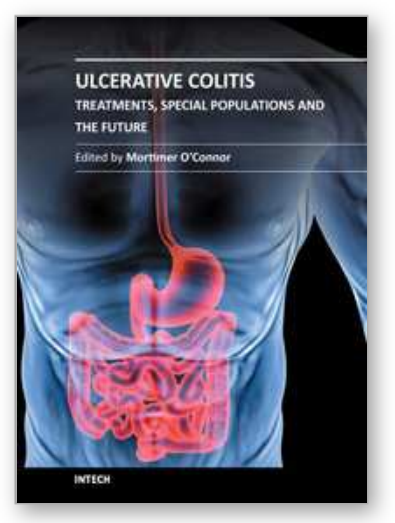

\author{
Ulcerative Colitis - Treatments, Special Populations and the Future \\ Edited by Dr Mortimer O'Connor
}

ISBN 978-953-307-739-0

Hard cover, 178 pages

Publisher InTech

Published online 02, November, 2011

Published in print edition November, 2011

This book is intended to act as an up to date reference point and knowledge developer for all readers interested in the area of gastroenterology and in particular Ulcerative Colitis. All of the chapter authors are experts in their fields of publication and deserve individual credit and praise for their contributions to the world of Ulcerative Colitis. We hope that you will find this publication informative, stimulating and a reference point for the area of Ulcerative colitis as we move forward in our understanding of the field of medicine.

\title{
How to reference
}

In order to correctly reference this scholarly work, feel free to copy and paste the following:

Francesca Zorzi, Emma Calabrese and Francesco Pallone (2011). New Biologic Drugs for Ulcerative Colitis, Ulcerative Colitis - Treatments, Special Populations and the Future, Dr Mortimer O'Connor (Ed.), ISBN: 978953-307-739-0, InTech, Available from: http://www.intechopen.com/books/ulcerative-colitis-treatments-specialpopulations-and-the-future/new-biologic-drugs-for-ulcerative-colitis

\section{INTECH}

open science | open minds

\section{InTech Europe}

University Campus STeP Ri

Slavka Krautzeka 83/A

51000 Rijeka, Croatia

Phone: +385 (51) 770447

Fax: +385 (51) 686166

www.intechopen.com

\section{InTech China}

Unit 405, Office Block, Hotel Equatorial Shanghai

No.65, Yan An Road (West), Shanghai, 200040, China

中国上海市延安西路65号上海国际贵都大饭店办公楼 405 单元

Phone: +86-21-62489820

Fax: +86-21-62489821 
(C) 2011 The Author(s). Licensee IntechOpen. This is an open access article distributed under the terms of the Creative Commons Attribution 3.0 License, which permits unrestricted use, distribution, and reproduction in any medium, provided the original work is properly cited. 